\title{
Single-Phase Trans-Z-Source AC-AC Converter
}

\author{
Hyunhak Shin, Minjae Joung \\ Gyeongbuk Institute for Advancement of Eco-friendly Auto parts Technology(GBITECH) \\ 120, Gongdan 7-ro, Jillyang-eup, Gyeongsan, Gyeongbuk (Korea) \\ Phone number:+82-53-802-2413, e-mail: jmj1006@gbitech.re.kr,hyunhak@gbitech.re.kr
}

\begin{abstract}
The existing Z-source or qZ-source PWM AC-AC converters have limited voltage gain because of the equivalent series resistance in the Z-source inductor. In order to obtain higher voltage gain than (q)Z-source AC-AC converters, a coupled inductor(or transformer) based Z-source AC-AC converter is proposed in this paper. By increasing turns ratio of the coupled inductor more than 1 , the proposed converter can obtain higher output voltage than (q)Z-source converters with the same duty ratio. A $120 \mathrm{~W}$ prototype AC-AC converter is built and tested to verify performances of the proposed converter.
\end{abstract}

\section{Key words}

AC-AC Conversion, Z-source, Coupled inductor, high voltage gain

\section{Introduction}

AC-AC converter can be divided largely the indirect AC$\mathrm{AC}$ converter with the direct AC-AC converter. The indirect $\mathrm{AC}-\mathrm{AC}$ converter is able to control both output voltage and frequency like matrix converters. However, it is necessary to use the direct PWM AC-AC converter in case of varying output voltage without regulating frequency [1]. For this case, it is recently introduced AC$\mathrm{AC}$ converters using Z-source inverters [2]-[5]. Figure 1 illustrates a conventional single phase Z- source AC-AC converter [4]. Conventional single-phase Z-source inverters have a function that output voltage can be stepup and down than input voltage. In addition, it is able to convert the phase of output voltage to same or opposite phase of input voltage. The circuit of Figure 1, although with these advantages, since the input voltage source and the switch has a structure connected in series, there is a drawback that the input current becomes discontinuous. Nowadays, to improve these it is introduced qZ-source AC-AC converters [6]-[11]. Figure 2 shows a scheme of conventional qZ-source AC-AC converter. Although qZsource AC-AC converter holds same voltage gain compared with Z-source AC-AC converter, it has an advantage of continuous input current due to series connection of input voltage and Z-source inductor $\left(\mathrm{L}_{1}\right)$. Also, input and output ground is common ground connection. Figure 3 shows waveforms of PWM signals for qZ-source AC-AC converter.

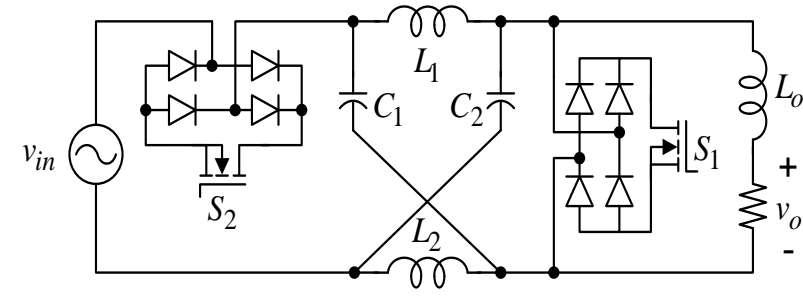

Fig. 1. Conventional single-phase Z-source AC-AC converter.

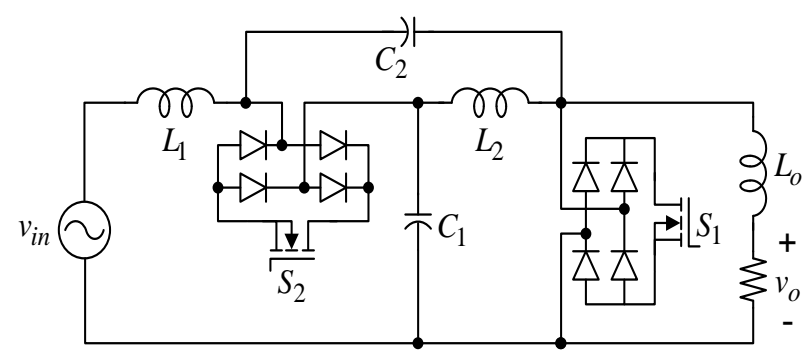

Fig. 2. Conventional single-phase qZ-source AC-AC converter.

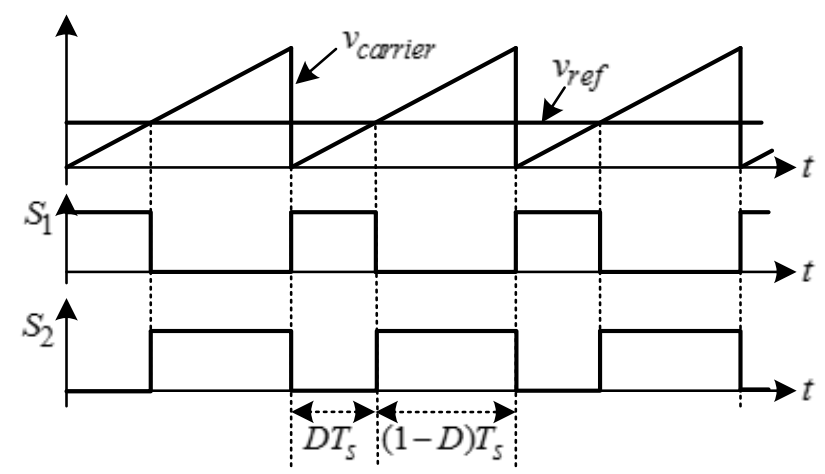

Fig. 3. Gate signal generation of $\mathrm{qZ}$-source AC-AC converter.

Switch S1 and S2 are turned on and off alternately like conventional PWM DC-DC converters. In Figure 1 and 2, the ratio of input and output voltage is shown as (1) considering parastic resistance of qZ-source inductors.

$$
\frac{v_{o}}{v_{i n}}=\left(\frac{1-D}{1-2 D}\right)\left\{\frac{1}{1+2 \frac{r}{R}\left(\frac{1-D}{1-2 D}\right)^{2}}\right\}
$$




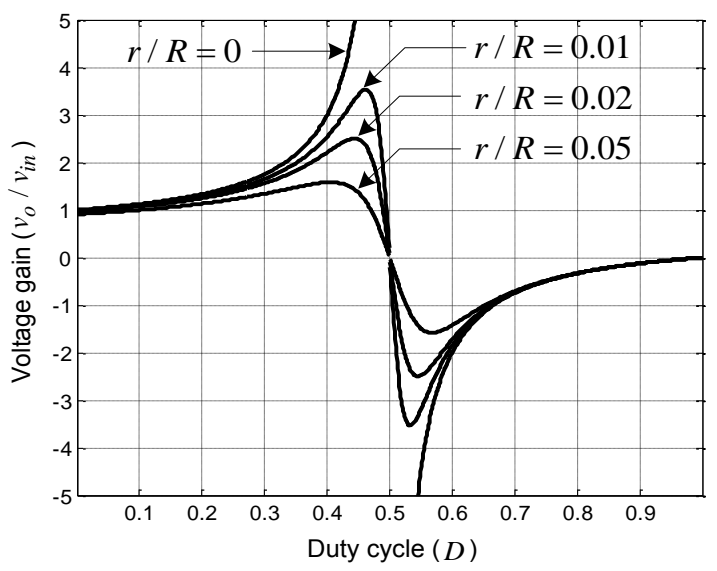

Fig. 4. Voltage gain of qZ-source AC-AC converter.

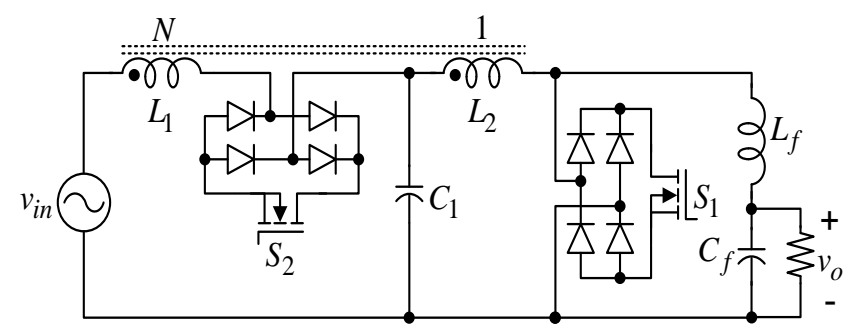

(a)

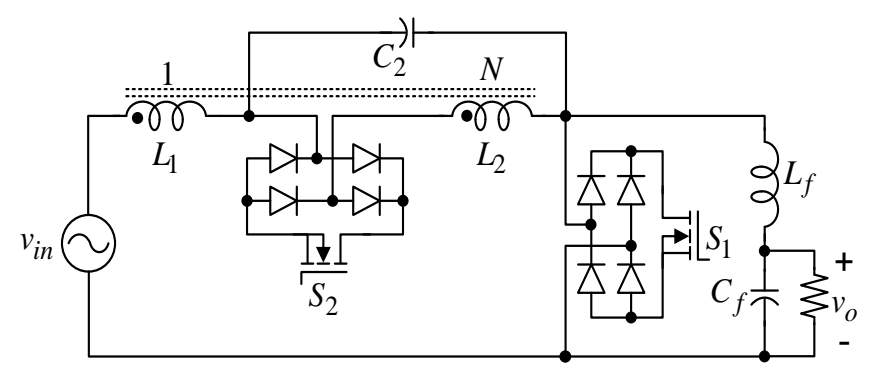

(b)

Fig. 5. Proposed trans-Z-source AC-AC converter. (a) Trans-Zsource AC-AC converter with removed C2. (b) Trans-Z-source AC-AC converter with removed $\mathrm{C} 1$.

D means duty ratio of switch $\mathrm{S} 1$ and $\mathrm{R}$ is load resistance. Figure 4 shows voltage gain curve of qZ-source AC-AC converter related with variations of $\mathrm{D}$ and $\mathrm{R}$. It is shown in Figure 4 that step-up region is always higher voltage gain than 1 in between $D=0$ and $D=0.5$. In between $D=0.5$ and $\mathrm{D}=1$, it can be step-up and down of voltage gain. In addition, the phase of output voltage is the opposite state $\left(180^{\circ}\right)$ in step-up and down regions. Output voltage gain of qZ-source topology is actually lower when duty ratio is over 0.45 due to parastic resistances of inductors for Z-source network even if Z-source topology is theoretically able to get infinite voltage gain. Therefore, conventional (q)Z-source AC-AC converters take a limitation of getting voltage gain more. This paper deals with trans-Z-source AC-AC converter to overcome limitation of voltage gain in conventional (q)Z-source ACAC converters.

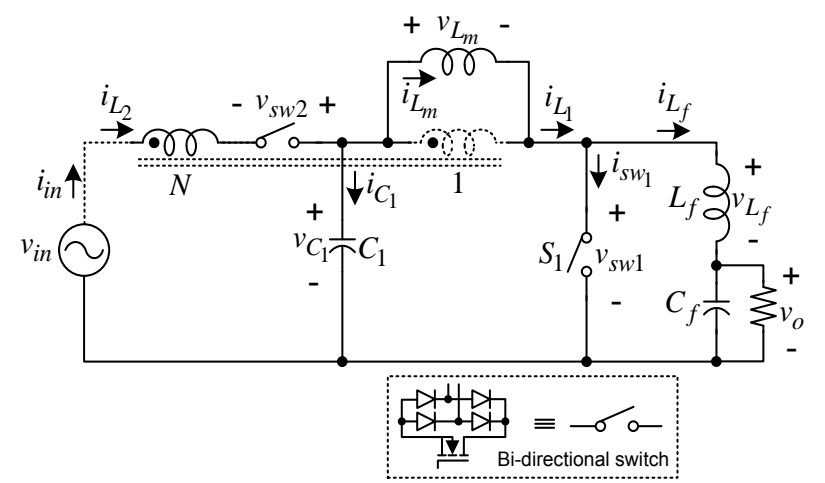

Fig. 6. Equivalent circuit of the proposed trans-Z-source AC-AC converter.

\section{Proposed Trans-Z-Source AC-AC Converter}

The voltage on inductors both $\mathrm{L}_{1}$ and $\mathrm{L}_{2}$ in Figure 1 and 2 is equivalent to voltage each other when switches turn on and off. Because of this, turns ratio of coupled inductor should be one-to-one. However, it is not necessary to keep one-to-one turns ratio of $\mathrm{L}_{1}$ and $\mathrm{L}_{2}$ if $\mathrm{C}_{1}$ or $\mathrm{C}_{2}$ is removed then $L_{1}$ and $L_{2}$ is coupled. It means that proposed topology can realize high voltage gain through different turns ratio of coupled inductor [12]. Figure 5 shows proposed two type trans-Z-source AC-AC converters according to removing $\mathrm{C}_{1}$ or $\mathrm{C}_{2}$. Figure 5-(a) illustrates with coupled with $\mathrm{L}_{1}$ and $\mathrm{L}_{2}$ removing $\mathrm{C}_{2}$. Figure 5-(b) illustrates with coupled with $L_{1}$ and $L_{2}$ removing $C_{1}$. The voltage gain of two cases in figure 5 is equally calculated and presented operations of converters similarly.

\section{A. Analysis of Operation Modes}

In this section, operation modes and voltage gain of trans$\mathrm{Z}$-source AC-AC converter are introduced. It is similar to be analyzed in Figure 5-(b) and the results are equivalent values. The turns ratio of primary and secondary side in coupled inductor is defined one-to- $\mathrm{N}$ similar to Figure 6. The coupled inductor is represented an equivalent circuit of magnetizing inductance $\left(\mathrm{L}_{\mathrm{m}}\right)$ and leakage inductance $\left(\mathrm{L}_{\mathrm{lk}}\right)$. For convenience parastic resistance $(\mathrm{r})$ and leakage inductance $\left(\mathrm{L}_{\mathrm{lk}}\right)$ are neglected. And it is shown bidirectional switches shortly as switches in Figure 6 . Figure 7 represents operation modes of proposed trans-Zsource AC-AC converter. Switch S1 in mode 1 on Figure 7 is turned on then switch S2 is turned off. Because of turned off S2 input current is not flowed to secondary side of coupled inductor. Therefore, electrical energy is charged in $\mathrm{L}_{\mathrm{m}}$ of coupled inductor. Equations of mode 1 are expressed as below.

$$
\begin{gathered}
v_{L_{m}}=v_{C_{1}} \\
v_{L_{f}}=-v_{o} \\
-i_{C_{1}}=i_{L_{m}}=i_{L_{1}}=i_{s w_{1}}+i_{L_{f}} \\
i_{\text {in }}=i_{L_{2}}=0 \\
v_{L_{m}}=\frac{v_{\text {in }}-v_{C_{1}}}{N}
\end{gathered}
$$




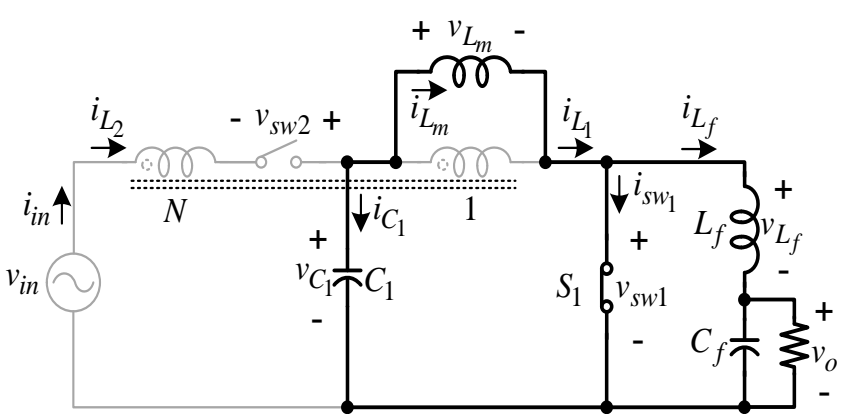

(a)

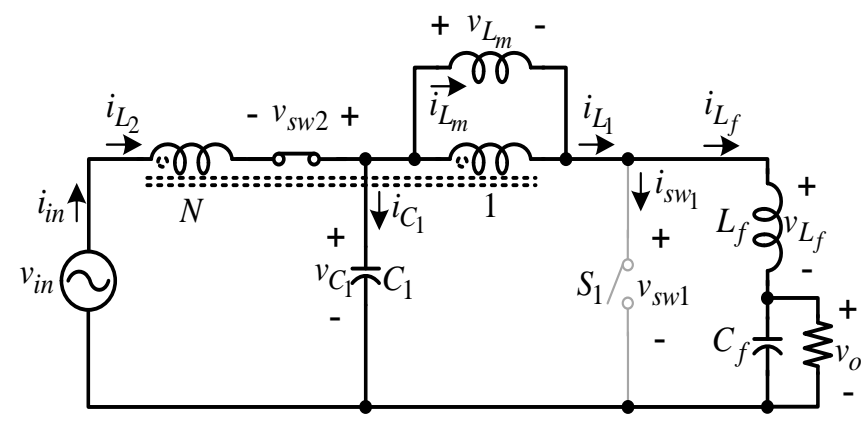

(b)

Fig. 7. Mode analysis of the proposed trans-Z-source AC-AC converter. (a) Mode 1. (b) Mode 2.



Fig. 8. Comparison of voltage gain of the trans-Z-source AC-AC converter and qZ-source AC-AC converter.

$$
\begin{gathered}
v_{L_{f}}=v_{C_{1}}-v_{L_{m}}-v_{o} \\
i_{C_{1}}=i_{L_{2}}-i_{L_{1}} \\
i_{\text {in }}=i_{L_{2}}=i_{C_{1}}+i_{L_{f}}
\end{gathered}
$$

It is get voltage gain of proposed trans-Z-source AC-AC converter as below using equation (2), (3), (6), and (7). D is defined duty ratio of switch $\mathrm{S} 1$.

$$
\frac{v_{o}}{v_{i n}}=\frac{1-D}{1-(1+N) D}
$$

Table I. - Voltage gain of the conventional qZ-source AC-AC converter and the proposed trans-Z-source AC-AC converter

\begin{tabular}{|c|c|c|}
\hline \multicolumn{2}{|c|}{ Output power } & $120 \mathrm{~W}$ \\
\hline \multicolumn{2}{|c|}{ Input voltage range } & $45-100 \mathrm{~V}_{\mathrm{rms}}$ \\
\hline \multicolumn{2}{|c|}{ Output voltage } & $110 \mathrm{~V}_{\mathrm{rms}}$ \\
\hline \multicolumn{2}{|c|}{ Switching frequency } & $20 \mathrm{kHz}$ \\
\hline \multicolumn{2}{|c|}{ Switching device } & DSEE30-12A \\
\hline \multicolumn{2}{|l|}{ Diode } & IRG7PH30K10PbF \\
\hline \multicolumn{2}{|c|}{ Z-source capacitor $\left(\mathrm{C}_{1}\right)$} & $6.8 \mathrm{uF}$ \\
\hline \multicolumn{2}{|c|}{ Output capacitor $\left(\mathrm{C}_{\mathrm{f}}\right)$} & $6.8 \mathrm{uF}$ \\
\hline \multicolumn{2}{|c|}{ Output inductor $\left(\mathrm{L}_{\mathrm{f}}\right)$} & $500 \mathrm{uH}$ \\
\hline \multirow{3}{*}{ Coupled inductor } & $\mathrm{L}_{\mathrm{m}}$ & $365 \mathrm{uH}$ \\
\hline & $\mathrm{L}_{\mathrm{lk}}$ & $2.35 \mathrm{uH}$ \\
\hline & $\mathrm{N}$ & 2 \\
\hline \multirow[t]{2}{*}{ Input filter } & $\mathrm{L}_{\text {in }}$ & $500 \mathrm{uH}$ \\
\hline & $\mathrm{C}_{\text {in }}$ & $6.8 \mathrm{uH}$ \\
\hline
\end{tabular}
with $\mathrm{r}=0 \Omega$.

\begin{tabular}{|c|c|c|}
\hline & $\begin{array}{c}\text { qZ-source AC-AC } \\
\text { converter }\end{array}$ & $\begin{array}{c}\text { Proposed trans-Z-source } \\
\text { AC-AC converter }\end{array}$ \\
\hline$\frac{v_{o}}{v_{i n}}$ & $\frac{1-D}{1-2 D}$ & $\frac{1-D}{1-(1+N) D}$ \\
\hline$\frac{v_{C_{1}}}{v_{i n}}$ & $\frac{1-D}{1-2 D}$ & $\frac{1-D}{1-(1+N) D}$ \\
\hline$\frac{v_{C_{2}}}{v_{i n}}$ & $\frac{D}{1-2 D}$ & Not applicable \\
\hline
\end{tabular}

Table II. - Electrical specifications of the proposed converter.

Figure 8 represents voltage gain curves compared proposed trans-Z-source AC-AC converter in case one-totwo turns ratio of coupled inductor with conventional (q)Z-source AC-AC converter. It is shown that proposed trans-Z-source AC-AC converter is high voltage gain than conventional (q)Z-source AC-AC converter in case of same duty ratio. Table $\mathrm{I}$ is shown voltage gain and capacitor voltage to compare proposed trans-Z-source AC-AC converter with conventional (q)Z-source AC-AC converter.

\section{Experimental Results}

Figure 9 shows a $120 \mathrm{~W}$ prototype proposed trans-Zsource AC-AC converter and Table II presents electrical specifications of the proposed converter. The output voltage is fixed $110 \mathrm{~V}_{\mathrm{rms}}$ and $60 \mathrm{~Hz}$ and varying the input voltage. Figure 10 presents the circuit diagram for experiments and input filters are added. Input filters are necessary to maintain continuous input current because removed capacitor C2 generates discontinuous input current. Turns ratio of coupled inductor in experiments is one-to-two and voltage gain is induced as below.

$$
\frac{v_{o}}{v_{\text {in }}}=\frac{1-D}{1-3 D}
$$

In Figure 11 it is shown waveforms of input voltage, output voltage and input current at $\mathrm{D}=0.25$ and $\mathrm{V}_{\text {in }}=47$ $\mathrm{V}_{\text {rms. }}$. Figure 12 represents waveforms at $\mathrm{D}=0.2$ and $\mathrm{V}_{\text {in }}=62 \mathrm{~V}_{\text {rms. }}$. Figure 13 shows waveforms at $\mathrm{D}=0.143$ and $\mathrm{V}_{\text {in }}=78 \mathrm{~V}_{\text {rms. }}$. It is different from phases of input current and voltage because this phenomenon depends on output loads. 


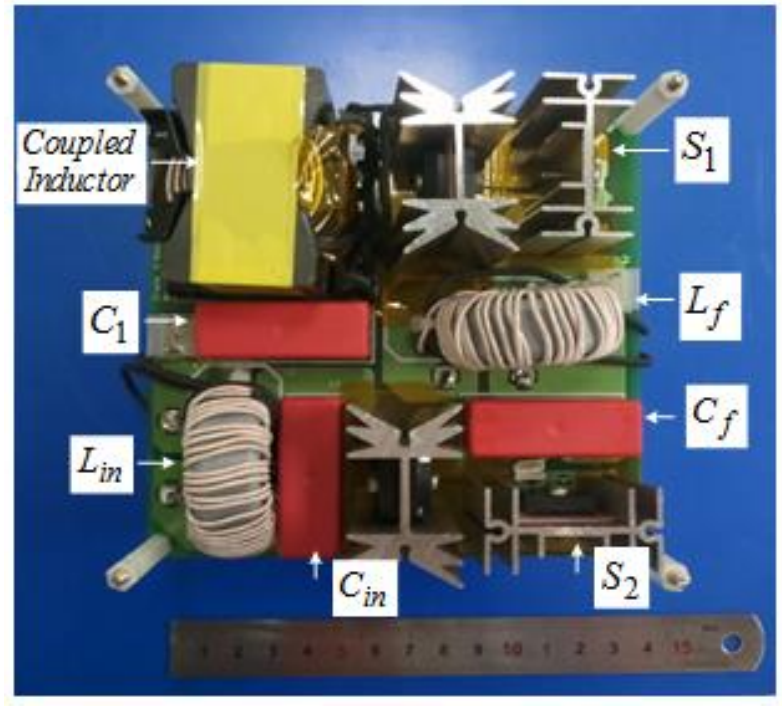

Fig. 9. Prototype circuit of the proposed trans-Z-source AC-AC converter.

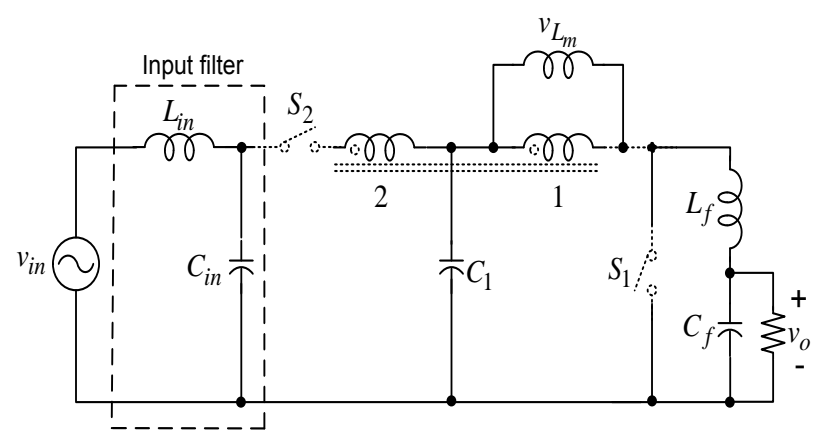

Fig. 10. Experimental circuit with an LC filter.

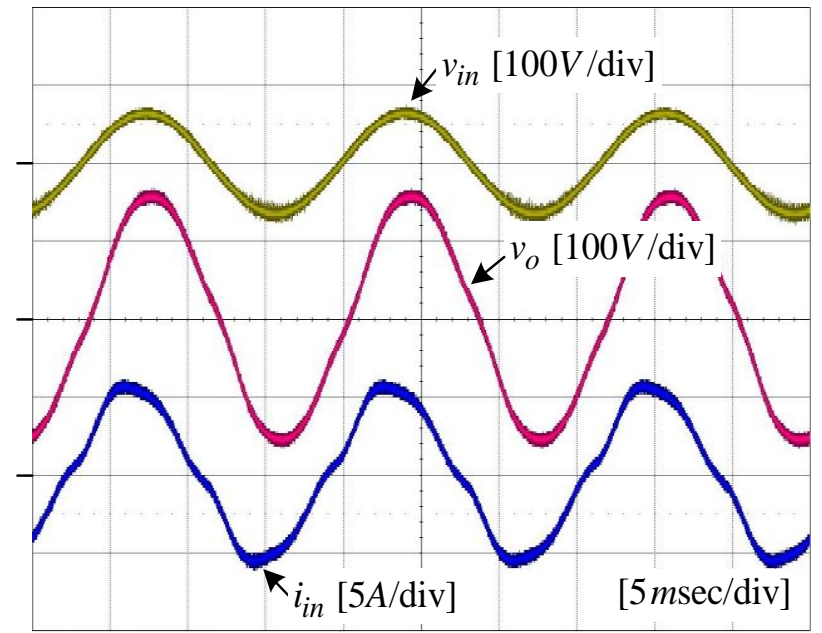

Fig. 11. Experimental waveforms of input and output voltage and input current of the proposed converter with $\mathrm{D}=0.25$ and $\mathrm{V}_{\text {in }}=47 \mathrm{~V}_{\text {rms. }}$.

The higher output voltage and current becomes closer in phase. Figure 14 represents output current and voltage waveforms of the proposed converter. In Figure 15 it is shown waveforms of primary side current in coupled inductor and switch $\mathrm{S} 1$ voltage at $\mathrm{D}=0.2$. Figure 16 shows both current waveforms of secondary side in coupled inductor and input current of the proposed converter.

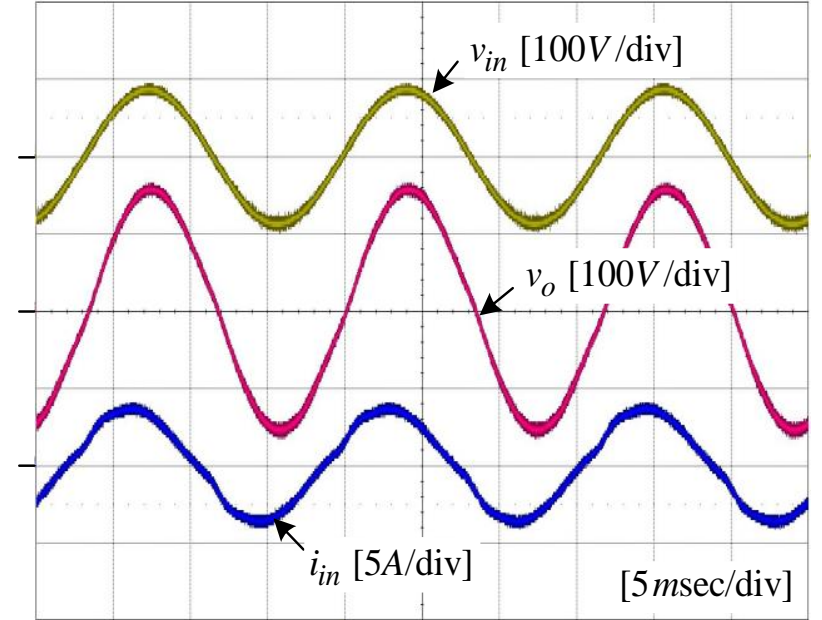

Fig. 12. Experimental waveforms of input and output voltage and input current of the proposed converter with $\mathrm{D}=0.2$ and $\mathrm{V}_{\text {in }}=62 \mathrm{~V}_{\text {rms. }}$.

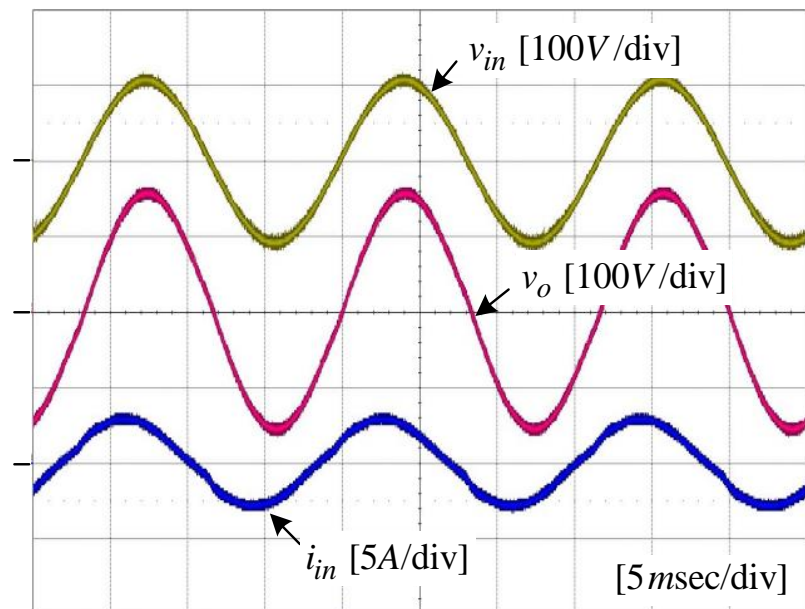

Fig. 13. Experimental waveforms of input and output voltage and input current of the proposed converter with $\mathrm{D}=0.143$ and $\mathrm{V}_{\text {in }}=78 \mathrm{~V}_{\text {rms }}$

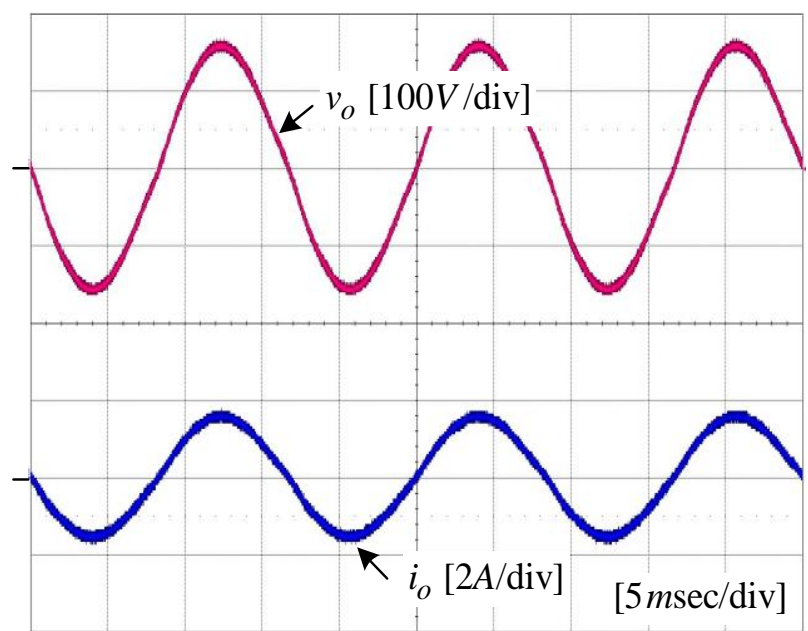

Fig. 14. Experimental waveforms of output voltage and output current with R load.

Previously described, LC filter is added for solving discontinuous input current. Table III presents efficiencies of the proposed converter. 


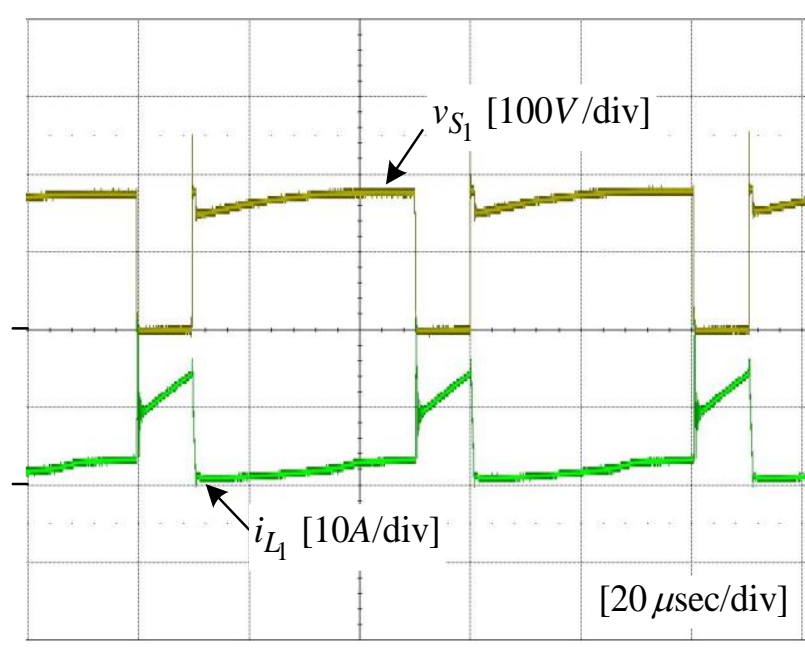

Fig. 15. Experimental waveforms of switch S1 voltage and inductor current with $\mathrm{D}=0.2$.

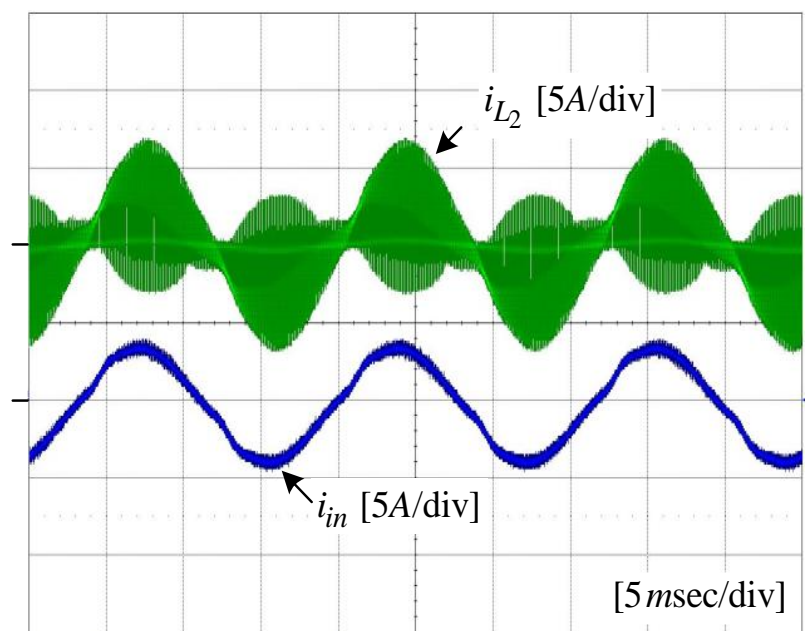

Fig. 16. Experimental waveforms of input current and inductor current with $\mathrm{D}=0.2$.

Table III. - Efficiency of the proposed converter versus input voltage for $\mathrm{V}_{\mathrm{o}}=110 \mathrm{~V}_{\mathrm{rms}}, \mathrm{P}_{\mathrm{o}}=120 \mathrm{~W}$.

\begin{tabular}{|c|c|c|c|}
\hline Input voltage [ $\mathrm{V}_{\mathrm{rms}}$ ] & 62 & 77 & 89 \\
\hline Efficiency [\%] & 83.3 & 88.1 & 91.5 \\
\hline
\end{tabular}

\section{Conclusion}

This paper addressed Trans-Z-source AC-AC converter included coupled inductors that has higher voltage gain than conventional (q)Z-source PWM AC-AC converters. The proposed converter can be achieved high voltage gain through increasing turns ratio of coupled inductors. Although the proposed converter needs more passive components like Capacitors or inductors it is effective to get stable output voltage under applications with unstable input voltage.

\section{Acknowledgement}

This research was financially supported by the "Green electronic car component development and research foundation construction program" through the Ministry of Trade, Industry\&Energy(MOTIE) and Korea Institute for Advancement of Technology(KIAT).

\section{References}

[1] F. Z. Peng, L. Chen and F. Zhang, "Simple topologies of PWM AC-AC converters", in Proc. IEEE Power Electron. Lett., 2003, Vol. 1, No. 1, pp. 10-13.

[2] F. Z. Peng, "Z-Source Inverter", in Proc. IEEE Transaction on Industry Applications, 2003, Vol. 39, Issue 2, pp. 504510.

[3] X. Fang, F. Z. Peng, "Novel Three-Phase Current-Fed ZSource AC-AC Converter", in Proc. Conf. Rec. IEEE PESC7, 2007, pp. 2993-2996.

[4] X. P. Fang, Z. M. Qian and F. Z. Peng, "Single-Phase Z source PWM AC-AC Converters", in Proc. IEEE Power Electron. Lett., 2005, Vol.3, No. 4, pp. 121-124.

[5] Y. Tang, C. Zhang and S. Xie, "Z-Source AC-AC converters Solving Commutation Problem", in Proc. IEEE Transaction on Power Electronics, 2007, Vol. 22, No. 6, pp. 2146-2154.

[6] J. Anderson, F. Z. Peng, "Four quasi-Z-Source inverters", in Proc. IEEE PESC 2008, pp. 2743-2749.

[7] S. Yang, F. Z. Peng, Q. Lei, R. Inoshita and Z. Qian, "Current-Fed Quasi-Z-Source Inverter With Voltage Buckboost and Regeneration Capability", in Proc. IEEE Transaction on Industry Applications, 2011, Vol. 47, No. 2, pp. 882-892.

[8] Y. Li, J. Anderson, F. Z. Peng and D. Liu, "Quasi-Z-source inverter for photovoltaic systems", in Proc. IEEE APEC, 2009, pp. 918-924.

[9] D. Cao, F. Z. Peng, "A Family of Z-source and Quasi-Zsource DC-DC Converter", in Proc. IEEE APEC, 2009, pp. 1097-1101.

[10] M. K. Nguyenn, Y. G. Jung and Y. C. Lim, "Single-phase AC-AC Converter Based on Quasi-Z-Source Topology", in Proc. IEEE Transaction on Power Electronics, 2010, Vol. 25, No. 8, pp. 2200-2210.

[11] M. K. Nguyen, Y. C. Lim and Y. J. Kim, "A Modified Single-Phase Quasi-Z-Source AC-AC Converter”, in Proc. IEEE Transaction on Power Electronics, 2012, Vol. 27, No. 1, pp. 201-210.

[12] W. Qian, F. Z. Peng and H. Cha, "Trans-Z-Source Inverters", in Proc. IEEE Transaction on Power Electronics, 2011, Vol. 26, No. 12, pp. 3453-3463. 